\title{
Preface
}

\section{Nurturing Collective Knowledge and Intelligence: Social phenomena and implications for practice}

Nowadays more than ever, during the global health crisis we are currently striving to overcome, we need to learn to adapt, communicate and innovate. We are going through historical times and we learn that we should always strive to understand what influences social phenomena, their factors, constantly changing our everyday reality and us.

Our current issue focuses on four different social phenomena that are in crisis, despite of COVID-19, and in need of our urgent attention; the environmental health issue, the European political landscape, the workplace burnout and the pervasion of social media in our children's everyday lives.

Human beings in times of crisis tend to come together, socially construct and collectively produce knowledge (Halas, 2002). 'An important component of the way humans perceive empirical reality is related to the principles they learn through education and other experiences' (Prevodnik \& Vehovar, 2020). Our individual realities therefore and our experiences, can contribute to a collective construction of knowledge and albeit intelligence. A Collective intelligence, that emerges from collaboration, exchange and collective efforts that can strongly contribute to the spread of knowledge from the individual to the collective' (Wikipedia, 2020). It thus has a direct impact on ourselves and how our perception of the issues surrounding us, changes over time. Our current global reality of living through COVID-19, will inevitably act as a catalyst for change, albeit a positive one (Mujahid, 2020; Vipin, 2020; Nelson, 2020) on a variety of reoccurring social issues.

Additionally, countries whilst sharing local knowledge, they learn to exchange, collaborate, react collectively and intelligently. Sharing allows knowledge to act then as a catalyst for change. Our issue hopes to share local knowledge on four different social phenomena with the view to coconstruct a collective one and adapt it in our own different realities. 
Sotirios Maipas signs the first paper of this issue with a research paper entitled «A $15 C$ 's Pathway of Sustainability in Environmental Health Management \& The Crucial Role of Higher Education Institutions». For him, innovation, which may be considered as a function of time, location, and explicit and tacit knowledge acquisition, is essential for the effective and sustainable management of environmental health issues. Then, apart from the emerging teaching and research priorities, the described pathway of 15 C's [(1) Consciousness of the urgency, (2) Comprehension of the complexity, (3) Confidence in our ability to change, (4) Capacity-building for decisionmaking, (5) Cooperation among stakeholders, (6) Carbon footprint reduction, (7) Circular economy adoption, (8) Corporate sustainability, (9) Creativity (Creative thinking and action), (10) Creation of resilient and adaptive communities, (11) Creation of sustainable living environments for all social groups, (12) Creation of new explicit and tacit knowledge, (13) Communication of the new knowledge, (14) Curriculum updates, and (15) Crisis management], suggests a framework towards sustainability in environmental health management and requires a strategic higher education institutions' contribution for a necessary societal transformation.

Emmanouil Takas, Gerasimos Prodromitis and Stamos Papastamou, sign the second paper entitled «Representing Europe in times of crisis. Rhetorical construction of "Europe" in the parliamentary discussions regarding the voting of the three Memoranda in Greece». The study investigates the Greek political rhetoric on the concept of 'Debt'. It is a detailed mixed methods political discourse analysis on the voting of the first, second and third Memoranda. It also very eloquently reveals the social and political tensions within the European Union.

The third paper by Kiahni McFadden and Dr Michael A. Altamirano, entitled «Situational Factors and Increased Workplace Burnout: A Study of Influences Affecting Current Younger Employees», brings forward a truly hidden issue that it is steadily and worryingly increasing globally. A study with employees from various sectors under the age of 50, reveal the relationship between workplace burnout and situational factors. The article adds to the existing knowledge and aims to understand workplace behavior, as burnout has dramatic consequences in professional efficacy and productivity.

Fancong Wang, Huayang Zhang and Xingyu Shi, from China, sign the last paper of this issue, entitled «An Empirical Study on the Influence of Social Media on the Interpersonal Relationship of Middle School Students». The paper refers to the development interpersonal interaction via social media practices and helps to add to our knowledge on social media interactions specifically with younger students. More specifically, 210 middle school students and 3 teachers from two middle schools in Guangzhou city of China took part in the research, to study the influence of social media 
on the development of interpersonal relationships with teachers and beyond. It allows as seeing how social media are a reality during school life and learning how the interactions of youngsters constantly evolve from a static to a more complex dynamic framework.

\section{Margarita K. Kefalaki \& Fotini Diamantidaki}

\section{References}

Bryn Nelson B. (2020). The positive effects of covid-19. BMJ 2020. doi: https://doi.org/10.1136/bmj.m1785 (Published 04 May 2020). Accessed 20 ${ }^{\text {th }}$ May 2020 https://www.bmj.com/content/369/bmj.m1785

Hałas, E. (2002). Symbolism and Social Phenomena: Toward the Integration of Past and Current Theoretical Approaches. European Journal of Social Theory, 5(3), 351-

366. https://doi.org/10.1177/136843102760513947

Prevodnik , K, \& Vehovar V. (2020) Methodological Issues When Interpreting Changes in Social Phenomena Over Time: Perceptions of Relative Difference, Absolute Difference, and Time Distance, Sociological Methods and Research, https://doi.org/10.1177/0049124120914948

Syed Mujahid H. (2020). Are there any positives of COVID-19? The News International. April 13, 2020. Retrieved 20th May 2020: https://www.thenews.com.pk/print/643668-are-thereany-positives-of-covid-19

Vipin T. (2020). 7 Positive Impacts to look forward to post the COVID-19 pandemic. Retrieved 20 ${ }^{\text {th }}$ May 2020: https://surveysparrow.com/blog/positive-impacts-to-look-forward-topost-covid-19-pandemic/

Wikipedia (2020). Collective Intelligence. Accessed $2^{\text {nd }}$ of June 2020: https://en.wikipedia.org/wiki/Collective_intelligence. 